hiervan een voorbeeld. Hunt (1972) observeerde drie bronnen van asymmetrie tussen de ondernemingen in de bedrijfstak die hij onderzocht: de mate van verticale integratie, diversificatie en produktdifferentiatie. Sommigen concluderen hieruit dat het logisch is dat in deze bedrijfstak vier strategische groepen worden onderscheiden. Toch is het duidelijk dat indien de ondernemingen zich onderscheiden op basis van een keuze ten aanzien van deze strategische variabelen die omschreven kan worden als 'sterk' versus 'zwak', bijvoorbeeld sterk verticaal geïntegreerd, sterk gediversifieerd met een zwakke produktdifferentiatie, er minstens acht mogelijke strategische groepen zijn. De relevante vraag die men dan had moeten onderzoeken is waarom er van de acht groepen in theorie slechts vier leefbaar zijn in de realiteit. Dit voorbeeld toont aan hoe gevoelig het onderzoek naar strategische groepen is voor het aantal strategische dimensies evenals de schaalopdeling binnen elke dimensie.

5 In een recente studie van Cool en Schendel blijkt dat de Amerikaanse farmaceutische industrie samengesteld is uit vier tot zes strategische groepen, naar gelang de beschouwde periode. De samenstelling van de groepen was ook onderhevig aan variatie: sommige research-georiënteerde ondernemingen uit de periode 1963-1969 zoals Merck 'zakten af' naar een 'me-too' strategie (eerder ook een middeltje ontwikkelen waar al bestaande therapieën zijn dan fundamenteel geneesmiddelenonderzoek doen). Omgekeerd waren er ook ondernemingen die vanuit een 'me-too' strategie zich een plaats wisten toe te eigenen bij de groep die recent (periode 1980-1982) doorgaat als research-oriented, met name Smith Kline.

6 Uit onderzoek van Schreuder e.a. (1989) bleek bijvoorbeeld hoe succesvolle ondernemingen zich onderscheidden van hun achterblijvende branchegenoten doordat zij andere, snellere en méér aanpassingen doorvoerden in het vooruitzicht van een structurele afzetwijziging op brancheniveau.

\section{Organisatie- advisering: een zelfversterkend mechanisme?}

\author{
Een discussiestuk
}

\section{Ir. F. Hordijk}

De organisatie-adviesbranche in Nederland maakt een enorme groei door. Volgens gegevens van de Raad van Organisatie Adviesbureaus ( $R O A$ ) is de totale omzet van de bij de ROA aangesloten bureaus in dertien jaar tijd meer dan verdrievoudigd, terwijl het aantal betrokken adviseurs in dezelfde periode (1975-1988) ruimschoots verdubbelde.

Juist in een dergelijk expansieve periode is het zinvol om kritisch bij het fenomeen organisatieadvieswerk stil te staan. Met dit artikel wordt getracht een aanzet te geven tot een discussie over het uiteindelijke effect van organisatie-advisering (waarbij uitsluitend aandacht wordt besteed aan 'externe' advisering). Voortbouwend op de theorie van twee filosofen wordt vanuit een onverwachte invalshoek, die van de gezondheids- en welzijnszorg, een controversiële stelling geponeerd: organisatie-advieswerk veroorzaakt ziekte-verschijnselen bij gezonde organisaties en kan de toestand van ongezonde organisaties op termijn alleen maar verergeren. In deel 1 van dit artikel wordt een korte schets gegeven van de theorie van de filosoof Illich. In deel 2 volgt een behandeling van de systeemtheorie van Boulding, die in deel 3 wordt gebruikt om met behulp van een veelgebruikte metafoor een schakel te leggen tussen Illich en organisatie-advieswerk.

Ir. F. Hordijk studeerde Bedrijfskunde aan de Technische Universiteit Eindhoven, studeert thans Economie aan de Katholieke Universiteit Brabant. Werkzaam bij KPMG Klynveid Overheidsgroep, 's-Gravenhage. Dit artikel is geschreven op persoonlijke titel. 


\section{MAB}

Deel 4 betreft een relatief uitgebreide behandeling van het fenomeen 'organisatie-doorlichting', waarbij een aantal denkbeelden van de Nederlandse filosoof Achterhuis aan de orde komt. Nadat in deel 5 de zogeheten 'macht van de deskundige' is besproken, wordt het betoog in deel 6 met een aantal conclusies en opmerkingen afgesloten.

\section{Illichs 'Grenzen aan de Geneeskunde'}

Als belangrijkste uitgangspunt voor de onderbouwing van de bovenstaande stelling dienen de ideeën van de Mexicaanse filosoof Ivan Illich. In zijn boek 'Grenzen aan de Geneeskunde' luidt Illichs centrale stelling, dat de zich steeds uibreidende medische wetenschap en de hierop berustende technische, institutionele gezondheidszorg het omgekeerde veroorzaken van wat zij beogen. Zij bedreigen de gezondheid van mensen in plaats van die te bevorderen. In het genoemde boek zet Illich met een indrukwekkende hoeveelheid feitenmateriaal zijn standpunt uiteen. Hij hanteert het begrip 'iatrogenese', dat in de medische vakliteratuur gebruikt wordt om nieuwe ziekten aan te duiden, waarvan artsen, ziekenhuizen en geneesmiddelen de verwekkers zijn. Hij onderscheidt aan deze iatrogenese drie aspecten: de klinische, de sociale en de structurele of culturele iatrogenese.

Onder klinische iatrogenese verstaat Illich de directe schade die medisch ingrijpen veroorzaakt, waardoor de mogelijke voordelen ervan veelal overschaduwd worden. In en buiten ziekenhuizen worden door artsen en verpleegkundigen vele fouten gemaakt met vérstrekkende gevolgen. Wie is bovendien bijvoorbeeld niet bekend met de ziekmakende nevenwerking van vele medicijnen? Een relatief groot aantal ziekenhuisopnamen vindt plaats enkel en alleen vanwege een negatieve reactie op voorgeschreven medicijnen. Sociale iatrogenese duidt op de ziekmakende effecten van de gezondheidszorg op het niveau van de samenleving. 'Sociale iatrogenese is aan het werk als van gezondheidszorg een gestandaardiseerd artikel gemaakt wordt, een voorraadartikel; als al het lijden 'gehospitali- seerd' wordt en er thuis geen plaats meer is voor geboorte, ziekte en dood; (...) of als lijden, rouw en genezen buiten de rol van patiënt gezien worden als een afwijking' (Illich). Bij de structurele of culturele iatrogenese gaat het op een nog fundamenteler niveau over de rol van het medisch systeem bij het vernietigen van de gezondheid. Het medisch systeem heeft de neiging de mens het vermogen zichzelf te genezen en zijn eigen levensomstandigheden te bepalen, te ontnemen.

Het medische systeem is volgens Illich zelfversterkend, immers waar iatrogenese optreedt, zal om meer artsen worden gevraagd om deze iatrogenese op te lossen, artsen die vervolgens zelf verschijnselen van iatrogenese teweegbrengen, etc. Zonder al te diep op Illichs filosofie in te gaan, kan gesteld worden dat hij een grote mate van 'deprofessionalisering' als de aangewezen richting ziet om dit zelfversterkende mechanisme te doorbreken. Minder geïnstitutionaliseerde macht bij artsen en andere hulpverleners, minder gespecialiseerde zorg, meer autonomie voor 'gewone' mensen, die veel meer dan nu verantwoordelijk zijn voor hun eigen en elkaars gezondheid en welzijn, zonder een al te grote tussenkomst van heteronome instituties en voorzieningen.

Ter afsluiting van de behandeling van het werk van Illich is het van groot belang te stellen dat Illich zeer beslist geen 'terug naar de natuur' bepleit. Het is onjuist te veronderstellen dat Illich de gehele moderne wetenschap en techniek af zou schrijven. Vanzelfsprekend heeft de medische welstand ook zeer belangrijke positieve kanten. Veel medische technieken kunnen echter uitstekend los van beroepsbevoogding gebruikt worden ter verbetering van de gezondheid van een bevolking, stelt Illich. Een klassiek voorbeeld betreft de Chinese 'blote voeten-dokters', die na een intensieve opleiding van drie weken in staat zijn de meest voorkomende aandoeningen te behandelen. Een groot gedeelte van wetenschap en techniek kan op deze wijze niet alleen als zodanig van zeer veel nut zijn; het kan ook de autonomie van bevolkingsgroepen, die door de voortschrijdende (medische) professionalisering wordt ondergraven, wezenlijk versterken. 


\section{MAB}

\section{Van Illich naar advieswerk: de systeemtheorie van Boulding}

Als gebruik wordt gemaakt van de zogeheten 'systeemhiërarchie' van Kenneth $\mathrm{E}$. Boulding, is de weg van Illich naar een beschouwing over het effect van organisatie-advieswerk onverwacht kort.

Boulding onderscheidt alle denkbare 'systemen' in toenemende mate van complexiteit in een hiërarchie met negen niveaus. Elk hoger systeemniveau draagt de kenmerken van alle lagere systeemniveaus in zich, maar voegt er bovendien nog een dimensie aan toe. Boulding deelt als volgt in:

1 Statische systemen, zoals een landkaart of een tafel;

2 Eenvoudige mechanische, dynamische systemen. Als voorbeeld een klok;

3 Cybernetische systemen, met als voorbeeld de temperatuurregeling van de centrale verwarming;

4 Open systemen, bijvoorbeeld een levende cel;

5 Genetisch-sociale systemen, waaronder planten;

6 Dierlijke systemen. Het systeem is het eigen bestaan gewaar;

7 Het menselijke systeem. Naast en boven al het voorgaande is dit niveau in staat tot abstract denken;

8 Sociale systemen: een organisatie, de maatschappij. Op dit niveau wordt de inhoud en bedoeling van informatie essentieel en doen kunst, symboliek en menselijke emoties hun intrede;

9 Transcedentele systemen: 'als dak op het huis', filosofie, systemen van waarden.

Als we organisatie-advisering definiëren als 'het geven van organisatiekundige bijdragen aan een cliënt-organisatie, gericht op de opbouw of het functioneren van die organisatie', dan kan met behulp van Bouldings systeemhiërarchie het voor dit artikel centrale uitgangspunt als volgt worden geformuleerd: organisatie-advisering is voor te stellen als medisch ingrijpen op één niveau boven het mens-systeem. Waar medisch handelen gericht is op een verbetering in de constitutie of het functioneren van een systeem van Bouldings zevende niveau, het mens-systeem, kan organisatie-advisering volgens de bovenstaande definitie worden gezien als een geheel van handelingen dat gericht is op een aanpassing van een systeem van het achtste niveau: een organisatie, van welke aard en met welke doelstelling dan ook. Opgemerkt moet hierbij worden dat de term 'functioneren', die we in het voorgaande zowel ten aanzien van mensen als van organisaties tegenkwamen, duidt op het feit dat die systemen zich in een omgeving bevinden. Mens-systemen functioneren in systemen van het achtste niveau (gezin, school, fabriek). Organisaties, op zich al van systeemniveau 8 , bewegen zich in een meeromvattend systeem op hetzelfde niveau (in casu de maatschappij). Overigens is het bijzonder moeilijk om een strikte scheidslijn te trekken tussen de organisatie-adviesbranche en vele 'aanverwante' branches (waaronder interim-management, opleidingen, personeelsselectie en automatisering). Bovenstaande definitie lijkt echter flexibel en tevens beperkend genoeg om de discussie niet op voorhand te laten vertroebelen.

\section{De metafoor van het menselijk lichaam als verbindende schakel}

Wie kent bij het denken over organisaties niet de metafoor van het menselijk lichaam, die het mogelijk maakt Illichs theorie bijna zonder aanpassing los te laten op organisatie-advieswerk? Gesproken wordt over 'zieke' en 'gezonde' organisaties, die worden 'doorgelicht' om tot een 'diagnose' te kunnen komen, waarna tot een 'operatie' kan worden besloten om de 'life-cycle' van de organisatie te beinvloeden. Niet voor niets is ook in de inleiding van dit artikel deze metafoor gebruikt: een herkenbare vorm van beeldspraak. Combineren we de theorieën van Illich en Boulding, dan kunnen de volgende conclusies worden getrokken.

1 Organisatie-advieswerk leidt tot klinische iatrogenese op systeemniveau 8. Advisering en andere beïnvloeding van buitenaf brengt vrijwel zonder uitzondering vormen van weerstand met 


\section{MAB}

zich mee. Onder meer passief of actief verzet, sabotage en verloop van personeel zijn het gevolg.

2 Organisatie-advieswerk veroorzaakt tevens een vorm van sociale iatrogenese. In de geest van Illichs woorden: meer organisatie-advieswerk vergroot de afhankelijkheid ten opzichte van dit werk, schept nieuwe, onnodige en 'pijnlijke' behoeften en zal organisaties op termijn zelfs het recht op een zelfstandig bestaan afnemen. Niet denkbeeldig is in die situatie de volgende reactie van een bank: 'Gezien de slechte financiële positie zullen wij de kredietaanvraag voor uw organisatie pas in overweging nemen nadat een reorganisatie heeft plaatsgevonden, die is begeleid door bureau $X, Y$ of $Z$ '. Organisaties wordt de kans ontnomen op een alternatieve, positief-hervormende wijze te functioneren in de maatschappij.

3 Organisatie-advieswerk brengt een vorm van structurele of culturele iatrogenese voort. Gelijk mensen pijn en ziekte niet meer als een onvermijdelijk onderdeel van leven en lichaam mogen zien, zo dienen ook in organisaties alle mogelijke problemen direct met hulp van buitenaf te worden geëlimineerd. De mogelijkheid om op lange termijn een zinvolle, constructieve werking van moeilijkheden te laten uitgaan, wordt organisaties ontnomen door die moeilijkheden direct op te lossen. De weg naar de totale afhankelijkheid van externe hulpverlening lijkt definitief ingeslagen.

\section{Een nadere beschouwing: Achterhuis en 'organisatiedoorlichting'}

In het licht van de filosofie van Illich en met name de uitwerking die Hans Achterhuis (eveneens filosoof, verbonden aan de Universiteit van Amsterdam en aan de Landbouwuniversiteit te Wageningen) hieraan heeft gegeven met betrekking tot de welzijnszorg, kan in het bijzonder het veelgeprezen instrument van de 'doorlichting' van organisaties nader onder de loep worden genomen.

Hiertoe wordt in hoofdzaak gebruik gemaakt van het boek 'Bedrijfsdiagnose' van P. M. Kempen, buitengewoon hoogleraar in de organisatieadviesprocessen aan de faculteit Bedrijfskunde van de Technische Universiteit Eindhoven. Niet alleen werd en wordt aan de daarin beschreven doorlichtingsmethode bijzonder veel aandacht in pers en vakpubliciteit besteed, ook biedt de context waarin deze methode beschreven is een uitstekend uitgangspunt voor een kritische benadering. Organisatiedoorlichting kan worden gezien als een beeldvormend organisatie-onderzoek; in een bundel over dit onderwerp wordt gesproken over 'diagnostische systemen waarmee men op een of andere manier de gezondheidstoestand van een organisatie in kaart wil brengen'. Een organisatie-onderzoek zal in veel gevallen een onderdeel van een organisatie-adviesproces vormen, maar deze begrippen zijn niet identiek. Enerzijds kan men een organisatie 'onderzoeken', zonder dat dit tot een advies hoeft te leiden, anderzijds komen organisatie-adviesprocessen voor zonder een expliciet daaraan verbonden onderzoeksfase.

Het feit dat in het onderstaande slechts de methode van Kempen in beschouwing wordt genomen, heeft overigens niets met een specifiek oordeel over deze methode van doorlichting van doen.

Kempen definieert zijn methode Bedrijfsdiagnose als 'een periodiek preventief onderzoek naar de huidige conditie van een organisatie, om op grond daarvan uitspraken te doen over haar toekomstig functioneren, teneinde daarin eventueel nu reeds aanleiding te vinden tot bijsturingsacties'. Met behulp van een uitgebreide vragenlijst, waarin zowel 'opinies' als 'feiten' ten aanzien van een aantal indicatoren worden vastgelegd, kan in een relatief kort tijdsbestek tot een oordeel over de conditie van een organisatie worden gekomen.

'Bij de diagnose ten behoeve van een preventiegericht onderzoek mist men de steun van een probleemstelling. De enige 'probleemstelling' is, hoe te voorkomen dat men in probleemsituaties terechtkomt', zo kan Kempen verder worden geciteerd. Kempen noemt het in een ander deel van zijn boek 'opvallend, dat Bedrijfsdiagnose altijd zwakke plekken heeft aangetoond. (...) het is (....) uitzonderlijk gebleken dat er niets aan de hand is'. Kempen wijst in die context terecht op de mogelijkheid dat 'Bedrijfsdiagnose' overbo- 


\section{MAB}

dige zaken signaleert, maar trekt vervolgens impliciet de conclusie 'dat er aan het functioneren van vrijwel elke organisatie wel wat mankeert'. En juist hier is het punt aangebroken waarop de overstap naar Achterhuis gemaakt moet worden.

Achterhuis is de auteur van het boek 'De markt van welzijn en geluk', waarin hij - grotendeels naar analogie van en voortbouwend op het werk van Illich - een beschouwing op de ontwikkeling van 'de welzijnssector' geeft. Achterhuis onderbouwt met een analyse van talloze nota's en rapporten een werkhypothese die na alle aandacht voor Illich niet meer vreemd zal overkomen. Deze luidt: 'Het welzijnsbeleid maakt mensen machtelozer en komt daardoor in strijd met de doelstelling die in het begrip welzijn ligt opgesloten'.

Voortbouwend op Illich besteedt Achterhuis veel aandacht aan het 'preventiedenken' in de medische en welzijnssector. Enkele citaten. 'De evaluatie van veel peperdure preventieprogramma's laat zien dat deze de gezondheid niet hebben bevorderd'. 'Op grond van een 'je-kunt-nooitweten-principe' handelt de arts gewoonlijk alsof het beter is dat hij zijn patiënten een ziekte toeschrijft, dan wanneer hij er een negeert. Dit levert een groot aantal mensen op die ten onrechte als ziek worden beschouwd'. 'Mensen die zich gezond en lekker voelen veranderen in angstige en afhankelijke patiënten, die zich als slaafse volgelingen van het medisch systeem gaan gedragen. (...) De verantwoordelijkheid voor het eigen lichaam en de eigen gezondheid wordt daardoor steeds verder ondergraven'.

Preventief onderzoek leidt tot meer werk in plaats van tot minder, hoe vreemd dit ook klinkt. Is het ook door Kempen aan zijn 'diagnose'-boek meegegeven credo 'voorkomen is beter dan genezen' dan niet langer meer van kracht? Het antwoord op deze vraag is te vinden in de professionele omschrijving van wat preventie precies inhoudt. Er kan een onderscheid worden gemaakt tussen primaire, secundaire en tertiaire preventie. Alleen primaire preventie komt overeen met wat men onder 'preventie' verstaat: het voorkomen van problemen. Goed beschouwd kent primaire preventie echter geen eindpunt. Steeds zal de 'preventiewerker' in kwestie (of het nu om een medi- cus, een welzijnswerker of een organisatie-adviseur gaat) nieuwe, 'kwetsbare' doelgroepen of aspecten van functioneren kunnen selecteren om zijn of haar werkzaamheden op los te kunnen laten. De feitelijke oneindigheid van primaire preventie - hetgeen overigens tegelijk zowel oorzaak als gevolg zou kunnen zijn van het ontbreken van een 'echte' preventietheorie - maakt dat men zich in de praktijk met name richt op secundaire preventie (het vroegtijdig opsporen en onderkennen van problemen) en tertiaire preventie (het zoveel mogelijk beperken van de schadelijke gevolgen van probleemsituaties).

Gaan we één stap hoger binnen de systeemhiërarchie, dan kan met behulp van de metafoor van het menselijk lichaam al hetgeen door Illich en Achterhuis over diagnostiseren en preventief handelen is gesteld van directe toepassing op organisaties worden verklaard.

\section{Diagnostiseren en de macht van de deskundige}

Misschien nog meer dan in de medische wetenschap zal het stellen van een 'diagnose' over een organisatie voor een groot deel van het inzicht en de ervaring van de betrokken onderzoeker afhangen. 'Echte' normen voor de gezondheid van een mens zijn nauwelijks vast te stellen, ergo laat staan voor organisaties. Niet voor niets heeft men bij een organisatie te maken met een systeem dat zich op een hoger niveau bevindt dan de mens. Veelal zal men zich moeten behelpen met bepaalde 'minimum-normen': als daar niet aan voldaan wordt, is dat zeker een indicator dat er iets mis is. Zoals in de geneeskunde bijvoorbeeld de lichaamstemperatuur en het gewicht objectief zijn vast te stellen, zo kan men bij organisaties als eerste een aantal financiële verhoudingsgetallen en de 'span-of-control' bepalen. Het uiteindelijke 'vonnis' over de gezondheid van mens en organisatie zal echter in alle gevallen subjectief worden gewezen door de betrokken onderzoeker. Dit ligt ook opgesloten in Kempens 'Bedrijfsdiagnose', in die zin dat het uiteindelijke oordeel over een organisatie voor een belangrijk deel gestoeld zal zijn op 'opinies' van de (externe) onderzoeker in kwestie. En het is juist hier waar Illich ten strijde 


\section{MAB}

trekt. 'De maatschappij heeft de arts het exclusieve recht gegeven te bepalen wat ziekte is, wie ziek is of ziek zou kunnen worden, en wat er met zulke mensen gedaan moet worden'. Gaat het voor organisaties ook niet hard die kant uit?

\section{Samenvatting en afsluiting}

latrogene verschijnselen ten aanzien van organisatie-advieswerk lijken een logische en causale verklaring te vormen voor de enorme groei van deze sector. Organisatie-adviseurs stellen vrijwel zonder uitzondering te streven naar een groter probleemoplossend vermogen bij hun cliënten, waardoor zij zelf op den duur overbodig worden. In werkelijkheid wordt het tegengestelde bereikt. De afhankelijkheid van externe 'professionals' wordt steeds groter, de eigen autonomie van organisaties neemt steeds verder af. Daarmee is tevens duidelijk dat de groei van de organisatieadviessector voorlopig niet stil zal staan: door het optreden van klinische, sociale en structurele of culturele iatrogenese is het mechanisme immers zelfversterkend.

Preventieve methoden voor organisatie-doorlichting en organisatie-diagnose veroorzaken het tegengestelde van wat zij beogen. Omdat er van 'echte', primaire preventie geen sprake kan zijn, worden meer problemen veroorzaakt dan voorkomen.

Slechts minder in plaats van meer professionele hulp kan het geschetste mechanisme doorbreken. Op het medisch vlak is dit aangetoond, ook voor de welzijnszorg blijkt dit zo te zijn (denk aan de vrijwel geheel op vrijwilligers draaiende AAzelfhulpgroepen voor mensen met alcoholproblemen). Ook met betrekking tot organisaties wordt al voorzichtig de weg van de deprofessionalisering ingeslagen. Als voorbeeld de Stichting Kleinnood te 's-Gravenhage, waarbij steeds meer kleine bedrijven voor hulp aankloppen. Het kenmerkende aspect van niet-professionaliteit: de hulp is gratis, waardoor van de zijde van de hulpverlener/adviseur veel minder snel sprake zal zijn van het kweken of instandhouden van een zekere afhankelijkheidsrelatie.

Oud-ondernemers en gepensioneerde managers van grote bedrijven verzorgen via de Stichting Kleinnood (verbonden aan het VNO) snelle, praktische hulp voor het midden- en kleinbedrijf, dat veelal financieel niet in staat is professionele adviseurs in te schakelen. In welzijnstermen gesproken: het geheel heeft in zekere zin een 'burenhulp'-karakter.

Achterhuis noemt het 'opvallend', dat medici in hun reactie op het verschijnen van Illichs 'Grenzen aan de Geneeskunde' diens feitenmateriaal nauwelijks bestreden. Hij citeert de medicus Van der Maas, die schreef dat het 'een waarheid als een koe is, dat de ontwikkeling van de medische wetenschap geen invloed heeft op de levensverwachting van een bevolking'.

Het is nauwelijks te verwachten dat de organisatie-advieswereld in ons land even lauw zal reageren op wat hierboven over die branche gesteld is.

\section{Literatuur}

Ivan Illich, Grenzen aan de Geneeskunde, Het Wereldvenster, 1978.

Hans Achterhuis, De markt van welzijn en geluk, Ambo, 1981.

K. E. Boulding, General systems theory, Management Science, 1956.

P. M. Kempen, Bedrijfsdiagnose alias management audit, Samsom, 1980.

Ton van den Berg, Preventieve psychosociale dienstverlening, Nelissen, 1977.

C. H. G. van Tilburg e.a. (red.), Organisatiedoorlichting in Nederland, Kluwer, 1983. 